\title{
COMPARISON OF THERMOELASTIC RESULTS IN TWO TYPES OF FUNCTIONALLY GRADED BRAKE DISCS
}

\author{
B.B. Sahari ${ }^{1,2}$, M.M. Shahzamanian ${ }^{1,2}$, M. Bayat $^{3}$, Z.N. Ismarrubie ${ }^{1}$ \\ and F. Mustapha ${ }^{4}$ \\ ${ }^{1}$ Mechanical and Manufacturing Engineering Department, Universiti Putra Malaysia \\ 43400 UPM, Serdang, Selangor, Malaysia \\ ${ }^{2}$ Institute of Advance Technology (ITMA), Universiti Putra Malaysia \\ 43400 UPM, Serdang, Selangor, Malaysia \\ ${ }^{3}$ Mechanical Engineering Department, University of Malaya \\ 50603 Kuala Lumpur, Malaysia \\ ${ }^{4}$ Aerospace Engineering Department, Universiti Putra Malaysia \\ 43400 UPM, Serdang, Selangor, Malaysia \\ Phone: 03-89467533, Fax: 03-89467536 \\ E-mail: barkawi@eng.upm.edu.my
}

\begin{abstract}
A thermoelastic simulation of functionally graded (FG) brake discs is performed using finite element (FE) ANSYS. The material properties of two types of FG brake discs are assumed to vary in both radial and thickness directions according to a power law distribution. The brake discs are in contact with one hollow pure pad disc. Dry contact friction is considered as the heat source. The proper thicknesses of pad discs are found to have full-contact status. The behaviour of the thermoelastic results for thickness and radial FG brake discs are compared. The results show that the behaviour of temperature and vertical displacement in these two types of FG brake discs are the same. However, the variations of radial displacement for different grading indices $n$ are not the same. The behaviour of other results are quite similar. Thus, it can be concluded that the variation direction of material properties in FG brake discs can affect the results.
\end{abstract}

Keywords: Functionally graded material, finite element method, brake disc, thermoelastic.

\section{INTRODUCTION}

Functionally graded materials (FGMs) are materials in which the volume fraction of two or more constituent materials varies smoothly and continuously as a function of position along certain dimension(s) of the structure from one point to another (Suresh and Mortensen, 1998; Reddy, 2000). Some work has been done using the finite element method to obtain the thermomechanical response of such materials. Shahzamanian et al. $(2010 \mathrm{a}, \mathrm{b})$ simulated a functionally graded (FG) brake disc in order to investigate the contact status and perform a thermoelastic analysis. The steps of FG brake disc simulation are described and results obtained for different values of contact stiffness factors and gradation indices. Yong and Ahn (2007) analysed the instability in FG brake discs with variations of material properties in the thickness direction and their results are presented in different times. Gao and Lin (2002) obtained the temperature 
distribution in a three-dimensional brake disc by using the finite element method (FEM), where the pure pad disc is considered as a sector.

In the present study, an FG hollow rotating brake disc with inner radius $r_{i}$, outer radius $r_{o}$, thickness, $h$ and axisymmetric with respect to the $z$-axis, was subjected to contact with one homogenous material hollow disc and the results analysed. The variation of material properties in the radius and thickness directions of the constituent components of two types of FG brake discs, are assumed to be represented by a power law distribution. Friction is considered to be the heat source that causes the thermal stresses. The thermoelastic results of FG brake discs with a variation of material properties in both the radial and thickness directions are compared.

\section{GRADATION RELATION}

In the present study, the variation of property, $\mathrm{P}$, of the material in the FG disc along the radial, $r$, and thickness, $\mathrm{z}$, directions is assumed to be of the following form in equations 1-2, respectively (Bayat et al., 2009a,b):

$$
\begin{array}{cl}
P(r)=\left(P_{o}-P_{i}\right)\left(\frac{r-r_{i}}{r_{o}-r_{i}}\right)^{n}+P_{i} ; & r_{o}<r<r_{i} \\
P(z)=P_{c}\left(\frac{2 z+h}{2 h}\right)^{n}+P_{m}\left(1-\left(\frac{2 z+h}{2 h}\right)^{n}\right) ; & n \geq 0 ;-\frac{h}{z}<z<\frac{h}{z}
\end{array}
$$

where, $P_{c}, P_{m}$ and $n$ are pure ceramic properties, pure metal properties and a grading index, respectively.

\section{FINITE ELEMENT METHOD}

Finite element ANSYS software was used to present the results. For thermomechanical loads, the plane 13 element is applied for the brake disc and pad disc. Targe 169 and Conta 171 elements are used for the brake and pad discs, respectively to define the contact surfaces. The FG brake disc is divided into two hundred elements. The mesh division for the radial and thickness FG brake disc is presented in Figures 1-2, respectively. Generally, increasing the number of the elements will improve the accuracy of the results. ANSYS Parametric Design Language (APDL) is used.

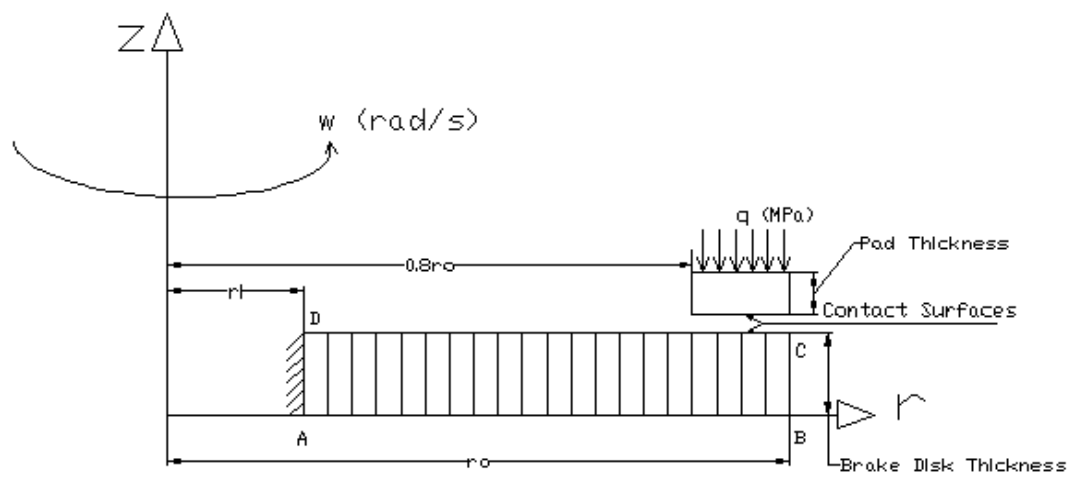

Figure 1. Mesh division for radial FG brake discs. 


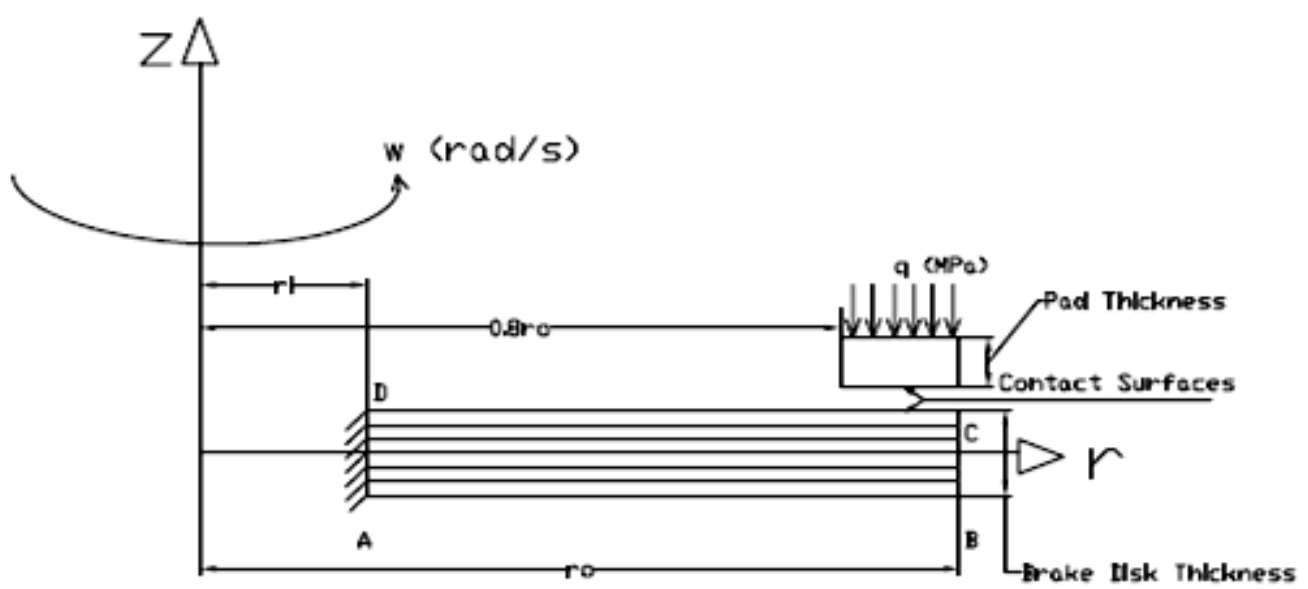

Figure 2. Mesh division for thickness FG brake discs.

In the thermal and structural cases, the rate of frictional dissipation $Q_{T}$ is given by:

$$
Q_{T}=H_{f} \times \mu \times q \times V \quad\left(\text { In this case } H_{f}=1\right)
$$

where: $V$ is the sliding rate, $H_{f}$ is the frictional dissipated energy converted into heat, $\mu$ is the friction coefficient and $q$ is the contact pressure.

\section{MECHANICAL BOUNDARY CONDITION}

The FG brake disc is mounted onto a shaft at the inner surface. Hence, the boundary conditions are as follows:

$$
\begin{gathered}
u_{r}=0 \text { at } r=r_{i}, \\
\sigma_{r}=0 \text { at } r=r_{o},
\end{gathered}
$$

\section{CONTACT STATUS CONSIDERATION}

To achieve a full-contact problem between the FG brake disc and pure pad disc, the contact status of both radial and thickness FG brake discs are investigated for different gradation indices (Shahzamanian et al., 2010a,b). In this case, the pad thickness value of 0.65 makes full-contact in the radial and thickness FG brake system for all of the values of gradation indices that are applied to obtain the thermomechanical results.

\section{RESULTS AND DISCUSSION}

An FG brake disc with $R_{o}=5 R_{i}$ and $h_{\text {brake }}=10 \mathrm{~mm}$ subjected to centrifugal force due to constant angular velocity $\omega=1000.0(\mathrm{rad} / \mathrm{s})$ and vertical pressure due to pad $q=1000.0 \mathrm{KPa}$, is considered. The friction coefficient between the pad and brake disc for a radial FG brake is $0.75 \leq \mu \leq 1.4$. For the FG brake disc, the ceramic surface is in contact with the pad disc. Thus, the friction coefficient between the pad and disc is equal to $\mu=0.75$. A pad disc with $R_{o, p a d}=1.25 R_{i, p a d}$ is considered when $R_{o, p a d}=$ 
$R_{o}$. The material properties applied are shown in Table 1 (Shahzamanian et al., 2010a,b).

Table 1. Material properties.

\begin{tabular}{lccccccc}
\hline \multicolumn{1}{c}{$\begin{array}{c}\text { Material } \\
\text { property }\end{array}$} & $\begin{array}{c}E \\
(\mathrm{MPa})\end{array}$ & $v$ & $\begin{array}{c}\rho \\
\left(\frac{\mathrm{Kg}}{\mathrm{m}^{3}}\right)\end{array}$ & $\begin{array}{c}\alpha \\
\left(\frac{1}{\mathrm{~K}}\right)\end{array}$ & $\begin{array}{c}K \\
\left(\frac{\mathrm{W}}{\mathrm{mK}}\right)\end{array}$ & $\begin{array}{c}C \\
\left(\frac{\mathrm{J}}{\mathrm{kg} . \mathrm{K}}\right)\end{array}$ & $\begin{array}{c}\mu \text { between } \\
\text { pad and } \\
\text { pure } \\
\text { material } \\
\text { disc }\end{array}$ \\
\hline $\begin{array}{l}\text { Partially } \\
\text { stabilised } \\
\text { zirconia (PSZ), }\end{array}$ & 151.0 & 0.3 & 5700 & $10 \times 10^{-6}$ & 2.0 & 400 & 0.75 \\
$\begin{array}{l}\text { Ceramic } \\
\text { aluminium, } \\
\text { metal }\end{array}$ & 70.0 & 0.3 & 2700 & $23 \times 10^{-6}$ & 209 & 900 & 1.4 \\
\hline
\end{tabular}

In the following sections, the results are presented in non-dimensional form by temperature, displacement, stress and strain normalised by factors: $T_{\max }-T_{\min }$, $\rho_{c r} \frac{\omega^{2} R_{\circ}{ }^{3}}{E_{c r}}, \rho_{c r} \omega^{2} R_{\circ}^{2}$ and $\rho_{c r} \frac{\omega^{2} R_{\circ}{ }^{2}}{E_{c r}}$, respectively.

The non-dimensional temperature for the radial and thickness FG brake disc at the first contact point $\left(\frac{R}{R_{\circ}}=0.8\right)$ are demonstrated in Figures 3-4, respectively.

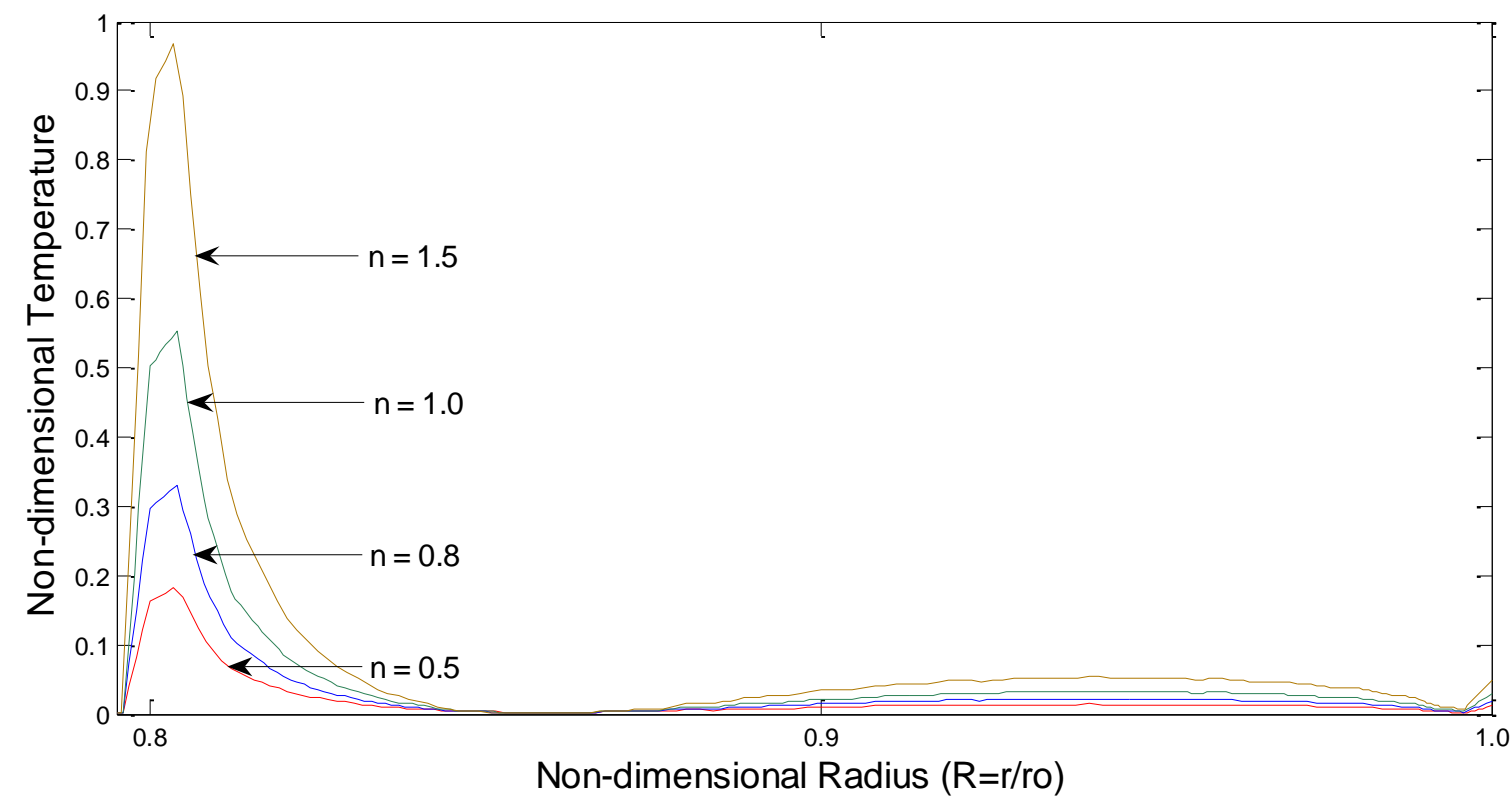

Figure 3. Non-dimensional temperature for radial FG brake discs.

It can be seen from Figures 3-4 that the behaviour of non-dimensional temperature at the first contact point is the same. Non-dimensional vertical displacement in the radial and thickness FG brake discs are shown in Figures 3-5. The results show that the variations of these displacements are similar to each other. Non-dimensional 
radial displacement for the radial and thickness FG brake disc is presented in Figures 78 , respectively.

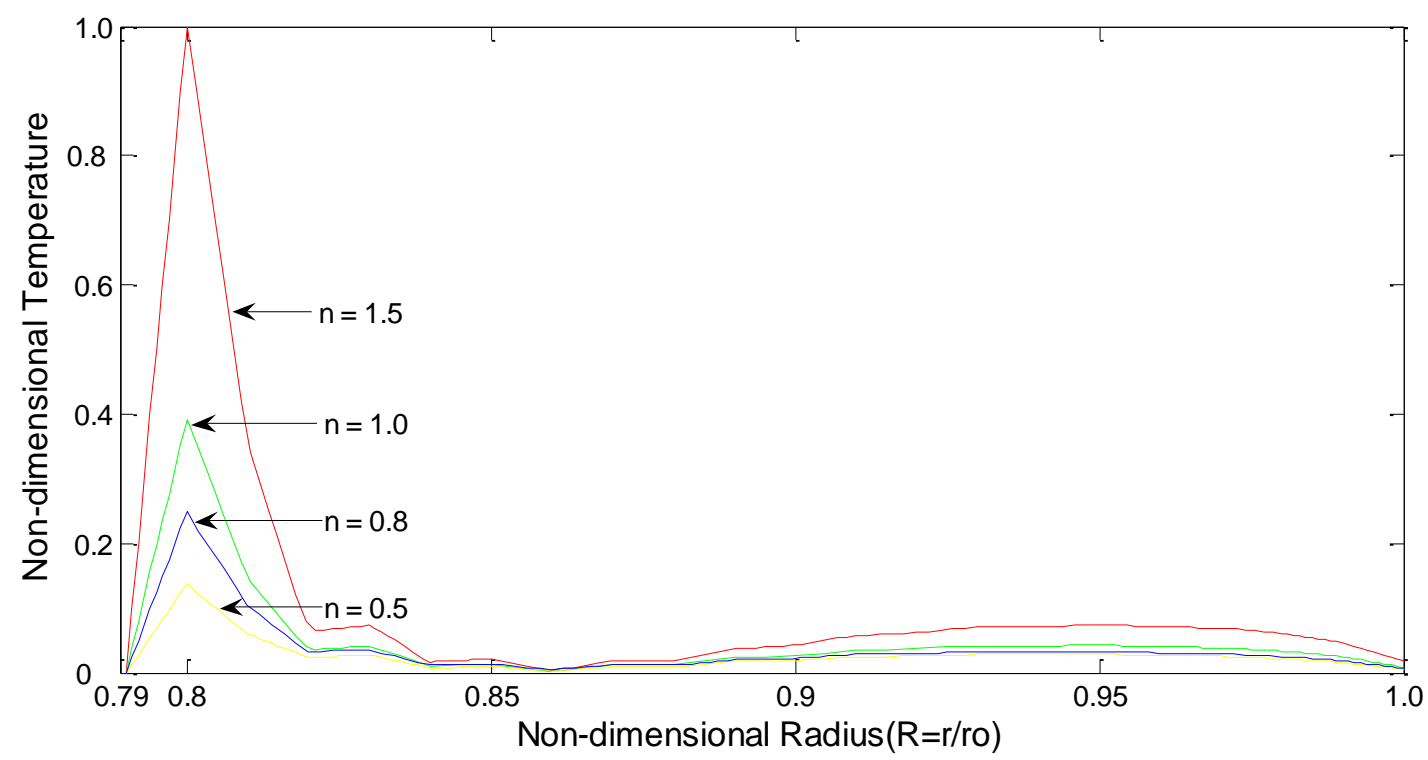

Figure 4. Non-dimensional temperature for thickness FG brake discs.

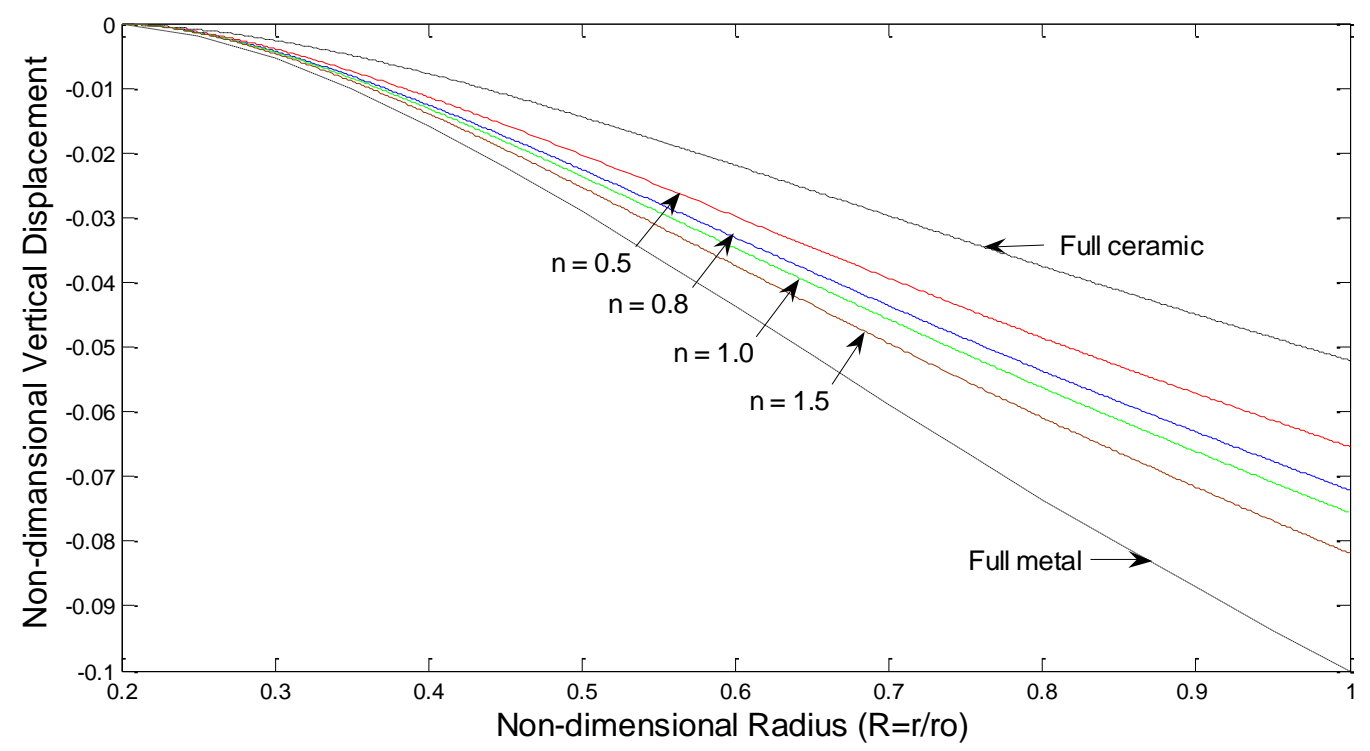

Figure 5. Non-dimensional vertical displacement in radial FG brake discs.

Figure 7 shows that by increasing the gradation indices, the non-dimensional radial displacement for the radial FG brake disc increases. However, this observation on the thickness FG brake disc is different. Figure 8 shows that the radial displacement for the thickness FG brake disc decreases with an increase of the grading index $n$ up to certain value and after that, increasing the grading index results in the radial displacement increasing up to that of a full metal disc. Non-dimensional radial stress for the radial and thickness FG brake discs are displayed in Figures 9-10, respectively. 


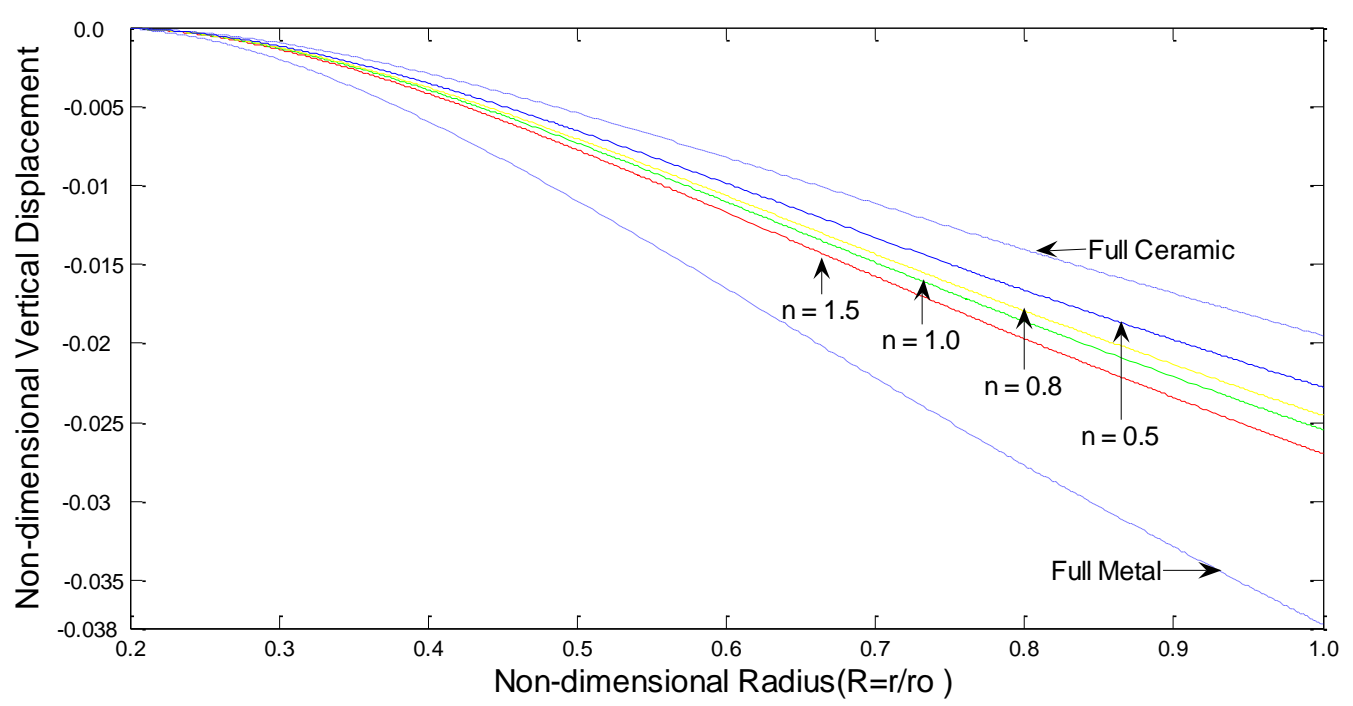

Figure 6. Non-dimensional thickness displacement in radial FG brake discs.

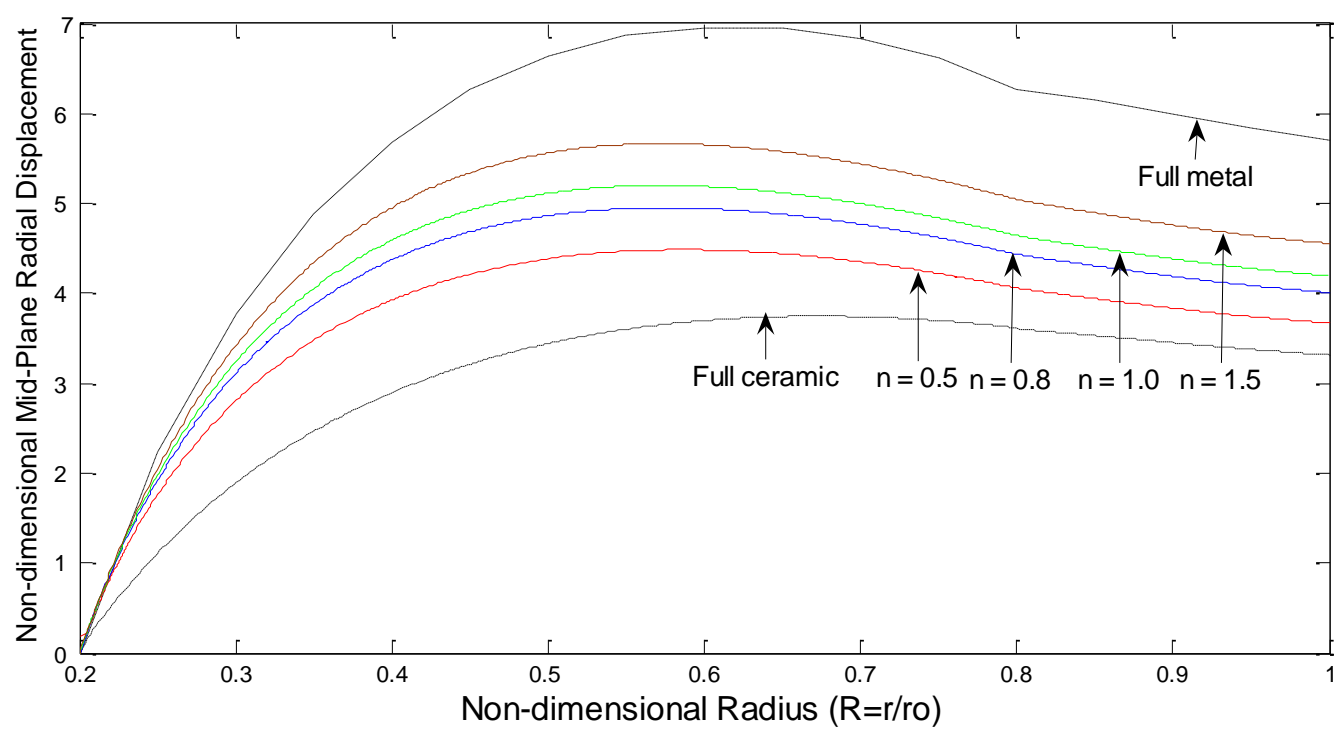

Figure 7. Non-dimensional radial displacement in radial FG brake discs.

It can be deduced from Figures 9-10 that the non-dimensional radial stress after the first contact point $\left(\frac{R}{R_{\mathrm{o}}}>0.8\right)$, in both the radial and thickness FG brake discs for all of the gradation indices, is equal to the value of that for full-metal and full-ceramic brake discs. It should be mentioned that before the first contact point $\left(\frac{R}{R_{\circ}}<0.8\right)$ for the radial FG brake disc, the non-dimensional radial stress for all of the gradation indices are equal and less than that for full-metal and full-ceramic brake discs. The reverse is the case the for thickness FG brake disc; the non-dimensional radial stress for all of the gradation indices are not equal and their values are bigger than for full-metal and fullceramic brake discs. It is noted that by increasing the gradation indices, the nondimensional radial stress increases. The non-dimensional out-of-plane shear stresses are shown in Figures 11-12 for radial and thickness FG brake discs in contact surfaces. 


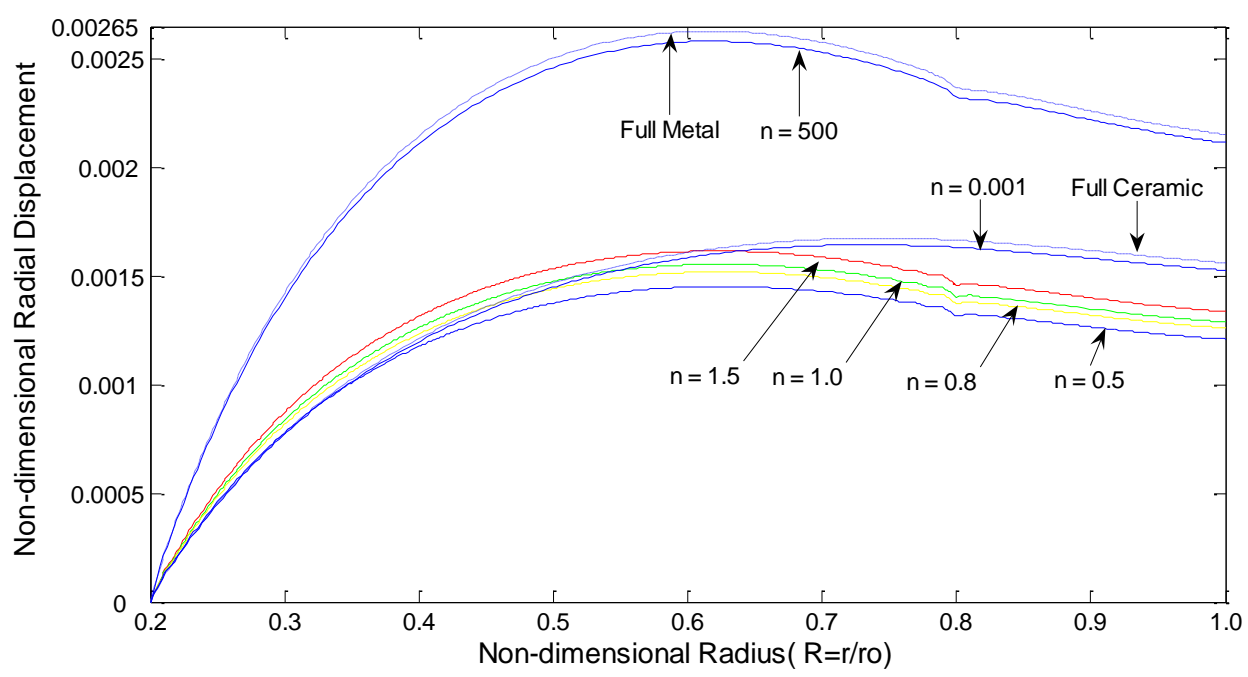

Figure 8. Non-dimensional radial displacement in thickness FG brake discs.

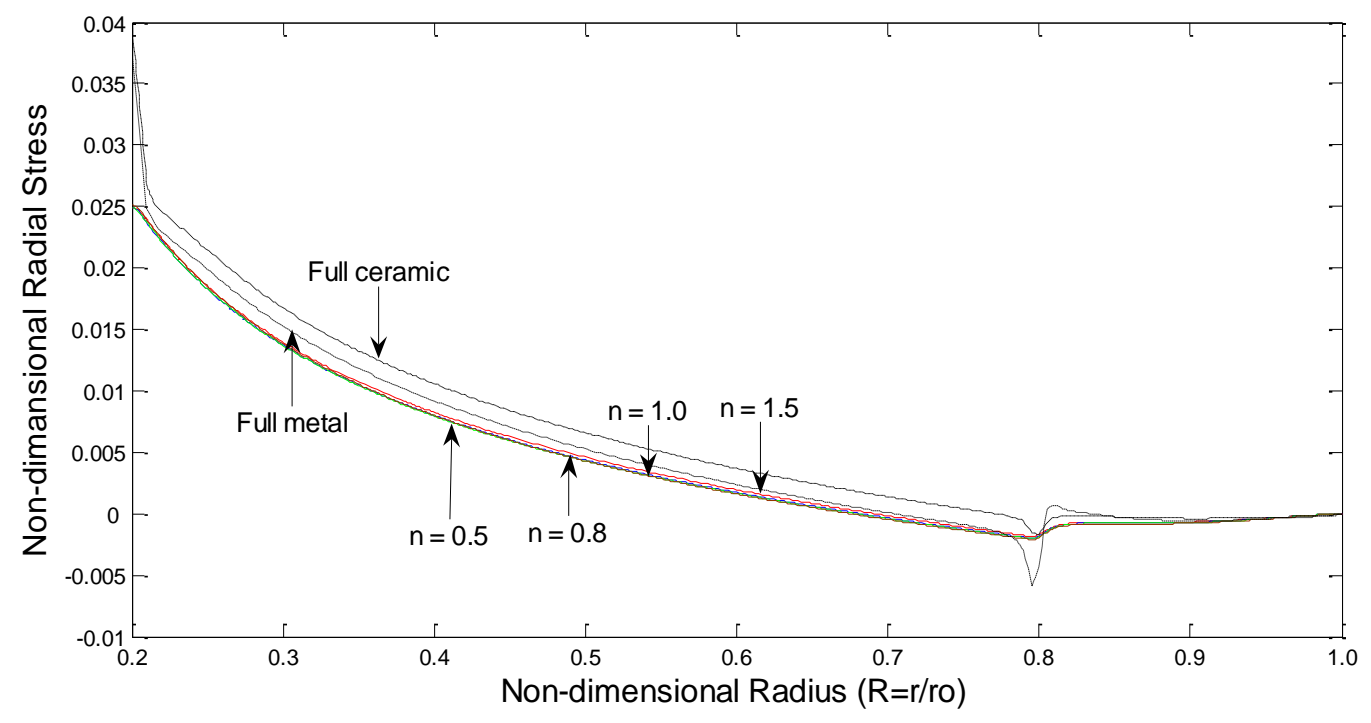

Figure 9. Non-dimensional radial stress in radial FG brake discs.

For the radial and thickness FG brake discs, the values of shear stresses of all gradation indices are equal. Prior to $\frac{R}{R_{\circ}}=0.8$, the non-dimensional shear stresses in the gradation indices for radial FG discs are less than those for full-metal and full-ceramic brake discs but for thickness FG discs the situation is reversed. At $\frac{R}{R_{\circ}}=0.8$, the shear stresses for thickness FG discs are smaller than for full-metal discs and shear stresses in radial FG discs are bigger than in full-ceramic discs. After $\frac{R}{R_{\circ}}=0.8$, the shear stresses of the radial and thickness discs have one intersection with the shears of the full-metal and full-ceramic discs. Initially, for radial FG discs, the shear stresses are greater than for full-ceramic and full-metal discs but for thickness FG discs this issue is different. The non-dimensional total radial stress for radial and thickness FG brake discs are presented in Figures 13-14, respectively. 


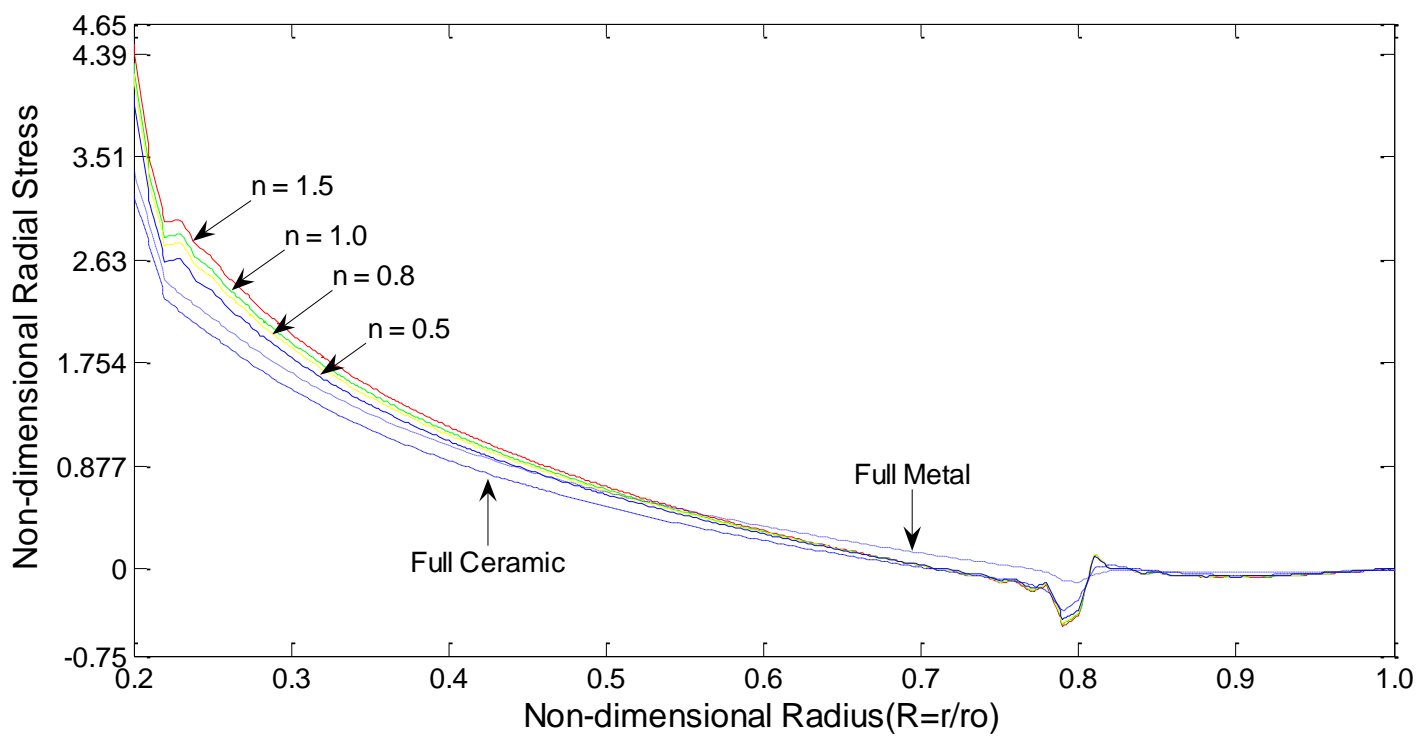

Figure 10. Non-dimensional radial stress in thickness FG brake discs.

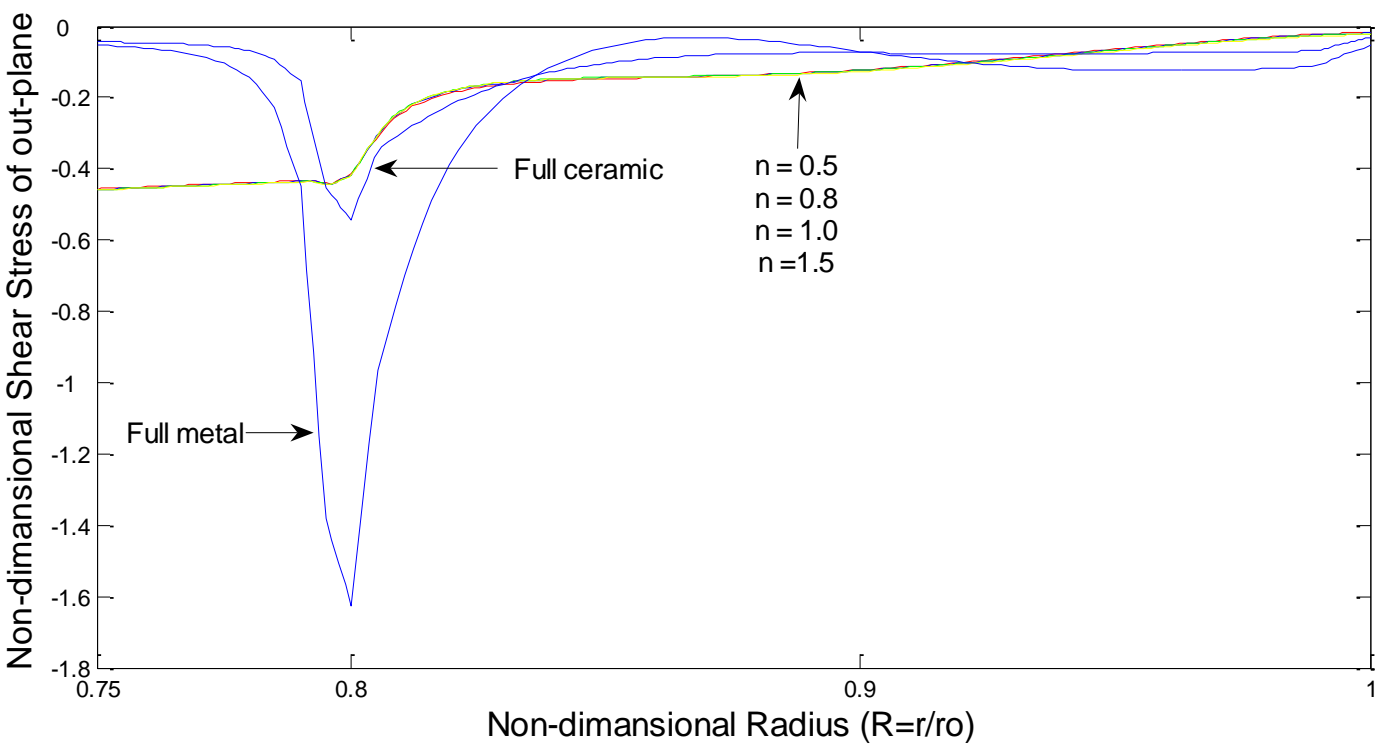

Figure 11. Non-dimensional shear stress of out-of-plane in radial FG brake discs.

Figures 13 and 14 show that the non-dimensional total radial strain for radial FG brake discs is closer to the non-dimensional total strain of full-metal brake discs. However, the non-dimensional total radial strain for thickness FG brake discs is closer to that of full-ceramic brake discs. 


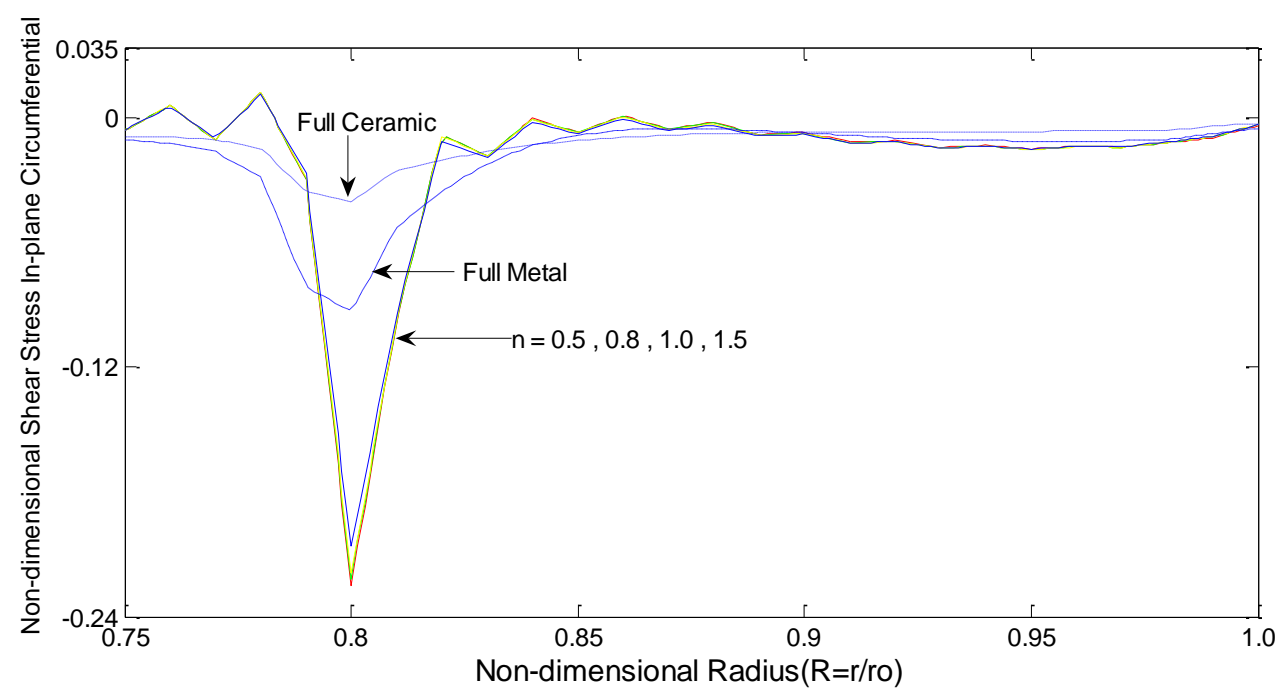

Figure 12. Non-dimensional shear stress of out-of-plane in thickness FG brake discs

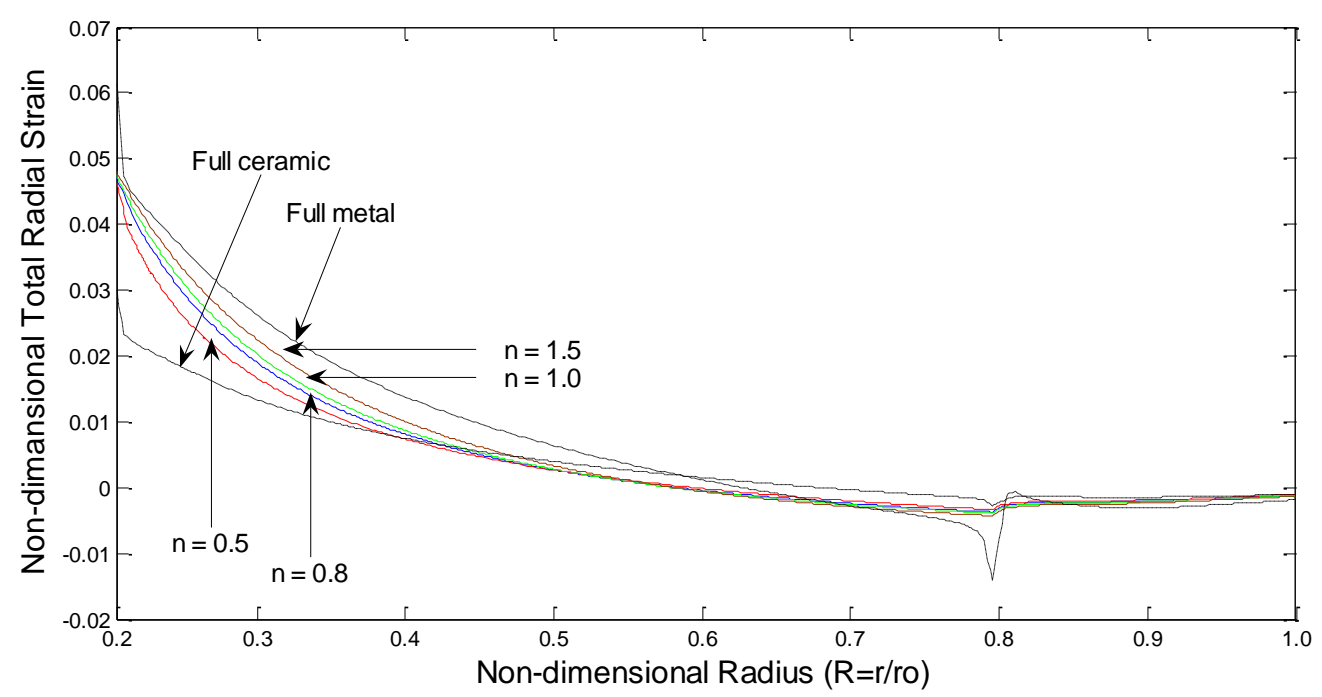

Figure 13. Non-dimensional total radial strain in radial FG brake discs

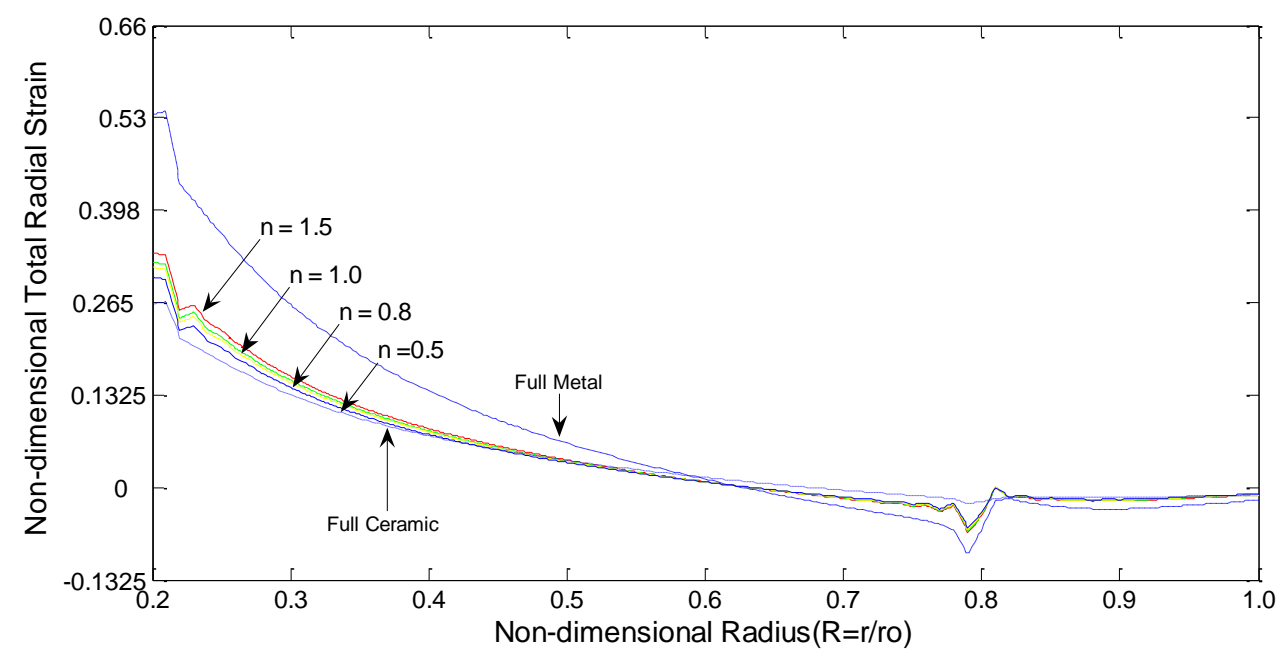

Figure 14. Non-dimensional total radial strain in thickness FG brake discs 


\section{CONCLUSIONS}

The thermoelastic analysis of two types of FG brake discs is studied. The material properties of radial FG brake discs vary in the radial direction and for thickness FG brake discs the material properties vary in the thickness direction. An FG brake disc dis in contact with a pure pad disc and dry friction is considered as the heat source. Initially, the contact status of the FG brake disc is investigated having full-contact status between the FG brake and pad disc. This analysis is done by ANSYS software. The results show that the behaviour of non-dimensional temperature and vertical displacement are similar for both radial and thickness FG brake discs. However, the non-dimensional radial displacement for radial and thickness FG brake discs are different. It is seen that nondimensional radial stress, shear stress of out-plane and total radial strain are quite similar. It can be concluded that the gradation of the constituent components is a significant factor in the thermomechanical response of FG brake discs.

\section{REFERENCES}

Bayat, M., Sahari, B.B., Saleem, M., Ali, A. and Wong, S.V. 2009a. Bending analysis of a functionally graded rotating disk based on the first order shear deformation theory. Applied Mathematical Model Journal, 33(11): 4215-4230.

Bayat, M., Sahari, B.B., Saleem, M., Ali, A. and Wong, S.V. 2009b. A thermo-elastic solution of a functionally graded variable thickness rotating disk with bending based on the first order shear deformation theory. Thin-Walled Structure, 47(5): $568-582$.

Gao, C.H. and Lin, X.Z. 2002. Transient temperature field analysis of a brake in a nonaxisymmetric three-dimensional model. Journal of Materials Processing Technology, 129: 513-517.

Reddy, J.N. 2000. Analysis of functionally graded plates. International Journal of Numerical Methods in Engineering. 47: 663-684.

Shahzamanian, M.M., Sahari, B.B., Bayat, M., Ismarrubie, Z.N. and Mustapha, F. 2010b. Transient and thermal contact analysis for the elastic behavior of functionally graded brake disks due to mechanical and thermal loads. Materials and Design, 31: 4655-4665.

Shahzamanian, M.M., Sahari, B.B., Bayat, M., Mustapha, F. and Ismarrubie, Z.N. 2010a. Finite element analysis of thermoelastic contact problem in functionally graded axisymmetric brake disks. Composite Structures, 92: 1591-1602.

Suresh, S. and Mortensen, A. 1998. Fundamentals of functionally graded materials. Institute of Materials (IOM) Communications Limited, London.

Yong, H.J. and Ahn, S.H. 2007. Frictionally-excited thermoelastic instability in functionally graded material. Wear, 262: 1102-1112. 